\title{
Frequency of Subdural and Epidural Hematoma in Brain Injury Via Computed Tomography in Trauma Center of DHQ Teaching Hospital Sargodha
}

\author{
Zeeshna Ali Haider Khan ${ }^{1} \quad$ Sajid Shaheen Malik ${ }^{1} \quad$ Muhammad Uzair $^{1} \quad$ S Muhammad Yousaf Farooq $^{1}$

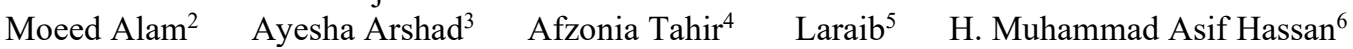 \\ 1.University Institute of Radiological Sciences \& Medical Imaging Technology, The University of Lahore, \\ Pakistan
}

\begin{abstract}
:
At least 10 million TBIs serious enough to result in death or hospitalization occur annually. The mortality associated with acute subdural hematoma has been reported to range from 36-79\%. Epidural hematoma occurs in approximately $2 \%$ of patients with head injuries and $5-15 \%$ of patients with fatal head injuries. Both can be caused by fall, motor vehicle crashes, assaults, blasts and sports activities. CT is best modality for diagnosis of brain injury. Objective:To measure the frequency of subdural and epidural hematoma in brain injury via computed tomography in trauma center of DHQ Teaching Hospital Sargodha.Methodology:In this descriptive study, among 137 patients of traumatic brain injury (TBIs) were selected with age and gender discrimination by convenient sampling, at Department of Radiology, DHQ Teaching Hospital Sargodha. Single slice Computed Tomography Toshiba asteion machine was used.Results: Out of 137 patients collected, 35 were females and 102 were males who visited emergency department due to brain Injury. It shows 25.5\% were females and males were 74.5\%.Out of 137 patients, $63.5 \%$ were injured with RTA and $35.8 \%$ came with the history of fall. $67.2 \%$ patients present with loss of consciousness, $67.9 \%$ patients with skull fractures and $73 \%$ with swelling. Out of 137 patients $85.4 \%$ develop SDH and 14.6\% develop EDH. Conclusion:In this study we conclude that male develop larger number of brain injuries than females. Most patients with history of RTA had epidural hematoma. Females most likely develop subdural hematoma. Most patients with brain injury later develop subdural hematoma.
\end{abstract}

Keywords: Subdural Hematoma, Epidural Hematoma, Traumatic Brain Injury(TBI), Road Traffic Accident(RTA) DOI: $10.7176 / \mathrm{JHMN} / 71-01$

Publication date: February $29^{\text {th }} 2020$

\section{INTRODUCTION}

Polytrauma due to road traffic accidents (RTA) is a leading cause of brain injury in teenagers and young adults. ${ }^{1}$ TBI may arise from physical damage by external blunt or penetrating trauma to the head, skull, dura, or brain or from acceleration-deceleration movement such as whiplash or coup-contrecoup, resulting in tearing or shearing of nerve fibers and bruising or contusion of the brain against opposite sides of the skull. Scraping of the brain across the rough bony base of the skull can cause contusion and can also affect the olfactory, oculomotor, optic, and acoustic nerves, leading to anosmia (total loss of the sense of smell, reduction of taste), double and/or blurred vision, and dizziness and/or vertigo. ${ }^{2}$ At least 10 million TBIs serious enough to result in death or hospitalization occur annually. An expected 57 million individuals worldwide have been hospitalized with at least $1 \mathrm{TBI}$, however the rate of living with TBI-related disability is still unknown. In the United States, an average of 1.4 million TBIs occur per year, including 1.1 million trauma centre visits, 235,000 hospitalizations, and 50,000 mortality rate. The main sources of TBI are falls, engine vehicle crashes, struck by or against occasions, and attacks, separately Blasts are a main source of TBI among dynamic obligation military work force in war zones. ${ }^{3}$ Sportsrelated TBI is an important public health problem because of the large number of people affected and the potential for serious sequelae, Brain injuries not only represent a serious disability for those involved but also place an enormous burden on society, often exacting a heavy economical, social, and emotional price. Since a cure is not attainable at this time, the only alternative is to develop intervention strategies to prevent or minimize these injuries. $^{4}$

Intracerebral hemorrhage (ICH) is associated with $40 \%$ early mortality and $80 \%$ disability. Hematoma expansion (HE) is a major determinant of early deterioration and death. ${ }^{5}$ Head Injury can be defined as, "a morbid situation, resulting from gross or ultra fine structural changes of the skull and its contents. ${ }^{6}$ The meninges are major connective tissue envelop that contribute the brain. Their salient features are to provide a protective coating to the blood brain barrier (BBB). ${ }^{7}$ There are two major types of hematoma named as subdural hematoma and epidural hematoma. Subdural Hematoma can arise either at the anterior or contracoup site. It is most commonly occur at the contracoup site. Any damage or injury to the superficial bridging veins results in the accumulation of blood between dura and arachnoid matter. SDHs usually found above the cerebral convexities, across the tentorium cerebella, and across the falxcerebri, in descending order of frequency. ${ }^{8}$ The classic CT appearance of an acute SDH is a crescent shaped homogeneously hyper dense extra axial collection that spreads diffusely over the affected 
hemisphere. With bilateral SDH, there may be no midline shift, and the cortical sulcal spaces are symmetrically effaced. ${ }^{9}$

Epidural hematoma is comparatively rare occurring as a consequence of head trauma. A trauma to the skull and the underlying meningeal vessels results in the formation of EDH. It is not because of brain damage. ${ }^{10} \mathrm{The}$ peak incidence of EDH is in the second decade, and the mean age of patients with EDH is between 20 and 30 years of age. EDH is a rare entity in patients older than 50 to 60 years of age. In pediatric patients, the mean age of patients harboring EDH is between 6 and 10 years and EDH is less frequent in very young children and neonates. EDH can result from injury to the middle meningeal artery, the middle meningeal vein, the diploic veins, or the venous sinuses. Historically, bleeding from the middle meningeal artery has been considered the main source for EDH. ${ }^{11}$ Computed tomography $(\mathrm{CT})$ is the standard initial diagnostic tool for patients with blunt trauma with suspected head injury. Once an intracranial abnormality has been identified on CT scan, patients are admitted to the hospital for observation, monitoring, and potentially medical and surgical therapy for severe injuries. ${ }^{12}$ With this study we will measure the frequency of different types of hematoma results from brain injury in our population so that appropriate management can be selected for the patient.

\section{Methods:}

In this descriptive study, among 138 patients of traumatic brain injury (TBIs) were selected with age and gender discrimination by convenient sampling, at Department of Radiology, DHQ Teaching Hospital Sargodha. Single slice Computed Tomography Toshiba asteion machine was used. The patients were included in this study if they had a clinical evidence of trauma above clavicles. Patients who have contraindications to CT machine i.e pregnancy and brain tumor were excluded.

\section{RESULTS}

Out of 137 patients collected, 35 were females and 102 were males. 87 out of 138 were injured due to RTA. 92 patients were presented with LOC. 49 were injured due to fall. 93 had fracture and 100 had swelling. 117 patients had SDH and 20 had EDH.

\begin{tabular}{|c|l|l|}
\hline & Frequency & Percent \\
\hline F & 35 & \\
M & 102 & 74.5 \\
Total & 137 & 100.0 \\
\hline
\end{tabular}

Table 1: Frequency Distribution of Gender

Table 2 shows out of 137 patients 13 patients (14.9\%) develop EDH who injured due to road traffic accident.

\begin{tabular}{|c|c|c|c|c|c|}
\hline & & & \multicolumn{2}{|c|}{ Epidural Hematoma } & \multirow[b]{2}{*}{ Total } \\
\hline & & & No & Yes & \\
\hline \multirow{4}{*}{$\begin{array}{l}\text { Road } \\
\text { Traffic } \\
\text { Accide }\end{array}$} & No & Count & 43 & 7 & 50 \\
\hline & & $\%$ within RTA & $86.0 \%$ & $14.0 \%$ & $100.0 \%$ \\
\hline & Yes & Count & 74 & 13 & 87 \\
\hline & & $\%$ within RTA & $85.1 \%$ & $14.9 \%$ & $100.0 \%$ \\
\hline \multirow{2}{*}{\multicolumn{2}{|c|}{ Total }} & Count & 117 & 20 & 137 \\
\hline & & $\%$ within RTA & $85.4 \%$ & $14.6 \%$ & $100.0 \%$ \\
\hline
\end{tabular}

Table 2: Frequency Distribution of RTA* EDH Crosstabulation 
Table 3 shows out of 137 patients $74(85.1 \%)$ patients develop SDH who injured due to RTA.

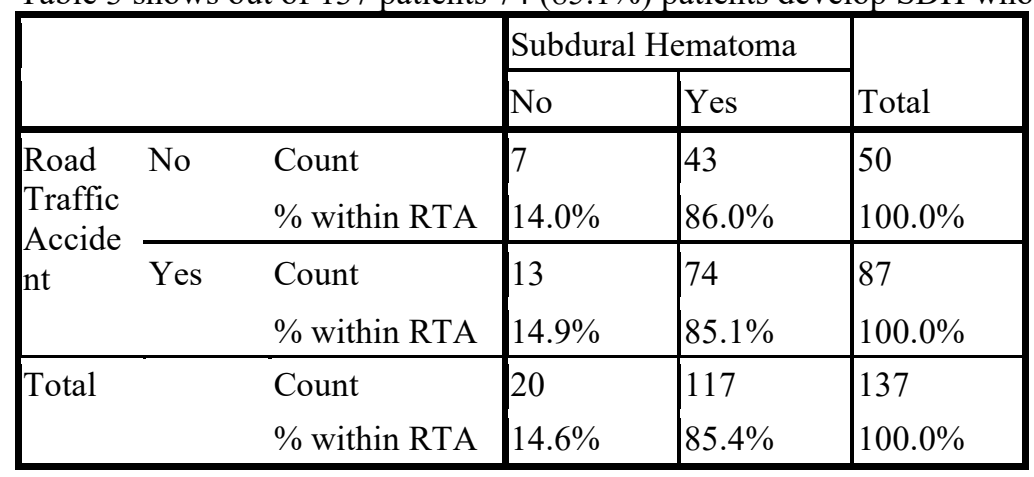

Table 3: Frequency Distribution of RTA* SDH Crosstabulation

Table 4 shows out of 137 Patients 7 patients (14.3\%) develop EDH who came with history of fall.

\begin{tabular}{|c|c|c|c|c|c|}
\hline & & & \multicolumn{2}{|c|}{ Epidural Hematoma } & \multirow[b]{2}{*}{ Total } \\
\hline & & & No & Yes & \\
\hline \multirow[t]{4}{*}{ Fall } & No & Count & 75 & 13 & 88 \\
\hline & & $\%$ within fall & $85.2 \%$ & $14.8 \%$ & $100.0 \%$ \\
\hline & Yes & Count & 42 & 7 & 49 \\
\hline & & $\%$ within fall & $85.7 \%$ & $14.3 \%$ & $100.0 \%$ \\
\hline \multirow[t]{2}{*}{ Total } & & Count & 117 & 20 & 137 \\
\hline & & $\%$ within fall & $85.4 \%$ & $14.6 \%$ & $100.0 \%$ \\
\hline
\end{tabular}

Table 4: Frequency Distribution of Fall* EDH Crosstabulation

Out of 137 patients 42 patients $(85.7 \%)$ develop SDH who came with the history of fall as shown in table 5.

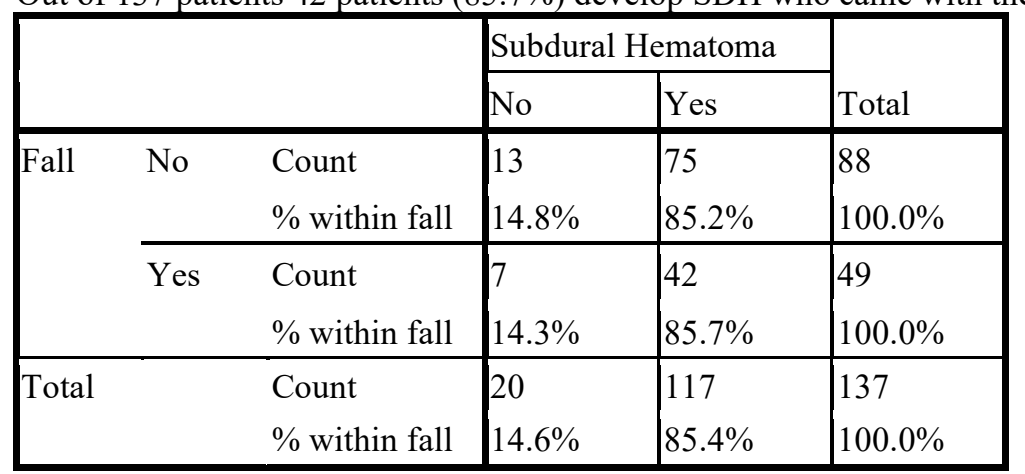

Table 5: Frequency Distribution of Fall* SDH Crosstabulation

Table 6 shows out of 137 patients 2 were female (5.7\%) who develop EDH and 18 were male (17.8\%) who develop $\mathrm{EDH}$.

\begin{tabular}{|c|c|c|c|c|c|}
\hline & & & \multicolumn{2}{|c|}{ Epidural Hematoma } & \multirow[b]{2}{*}{ Total } \\
\hline & & & No & Yes & \\
\hline \multirow[t]{4}{*}{ Gender } & $\mathrm{F}$ & Count & 33 & 2 & 35 \\
\hline & & $\%$ within gender & $94.3 \%$ & $5.7 \%$ & $100.0 \%$ \\
\hline & M & Count & 84 & 18 & 102 \\
\hline & & $\%$ within gender & $82.4 \%$ & $17.6 \%$ & $100.0 \%$ \\
\hline \multirow{2}{*}{\multicolumn{2}{|c|}{ Total }} & Count & 117 & 20 & 137 \\
\hline & & $\%$ within gender & $85.4 \%$ & $14.6 \%$ & $100.0 \%$ \\
\hline
\end{tabular}

Table 6: Frequency Distribution of Gender* EDH Crosstabulation 
Table 7 shows out of 137 patients 33 were female (94.3\%) who develop SDH and 84 were male (82.4\%) who develop SDH.

\begin{tabular}{|c|c|c|c|c|c|}
\hline & & & \multicolumn{2}{|c|}{ Subdural Hematoma } & \multirow[b]{2}{*}{ Total } \\
\hline & & & No & Yes & \\
\hline \multirow[t]{4}{*}{ Gender } & $\mathrm{F}$ & Count & 2 & 33 & 35 \\
\hline & & $\%$ within gender & $5.7 \%$ & $94.3 \%$ & $100.0 \%$ \\
\hline & M & Count & 18 & 84 & 102 \\
\hline & & $\%$ within gender & $17.6 \%$ & $82.4 \%$ & $100.0 \%$ \\
\hline \multirow{2}{*}{\multicolumn{2}{|c|}{ Total }} & Count & 20 & 117 & 137 \\
\hline & & $\%$ within gender & $14.6 \%$ & $85.4 \%$ & $100.0 \%$ \\
\hline
\end{tabular}

Table 7: Frequency Distribution of Gender* SDH Crosstabulation

\section{Discussion}

Out of 137 patients collected, 35 were females and 102 were males who visited emergency department due to brain Injury. It shows $25.5 \%$ were females and males were $74.5 \%$.Out of 137 patients, $63.5 \%$ were injured with RTA and $35.8 \%$ came with the history of fall. $67.2 \%$ patients present with loss of consciousness, $67.9 \%$ patients with skull fractures and $73 \%$ with swelling. Out of 137 patients $85.4 \%$ develop SDH and $14.6 \%$ develop EDH. A crosssectional observational investigation Gupta Prashant K, et.al included 382 patients with head damage who were conceded in the crisis branch of a multispecialty tertiary consideration clinic, from September 2008 to September 2010. The regular age gathering was between $20-50$ years $(70.9 \%)$, and under $13 \%$ were older ( $>60$ years) patients. Males had higher frequency of head injury than females (306 versus 76). Cerebral edema was recognized in $63.4 \%$ of the cases, trailed by skull break (62\%), hemorrhagic injury (46.3\%), and epidural hematoma (30.4\%). Epidural hematoma was available in temporo-parietal district in $48.0 \%$ patients, $32 \%$ in frontal area, and $20 \%$ in parietooccipital locale. In about portion of the patients, intracerebral hematoma was available in the frontal area. ${ }^{1}$ Johannes Leitgeb, M.D., et.al conducted a study. There were 863 data sets in the database. Of these, outcome was not recorded in 18 patients, 9 patients died prior to ICU admission, and 98 patients had only moderate TBI (GCS scores of 9-12 after admission); this left 738 patients for analysis. Of these, $360(48.8 \%)$ had an acute SDH on their CT scan and were selected for this analysis. Demographic data for the 2 groups of patients are given in Table 1. About $70 \%$ of the patients were male, and there was no significant difference between the groups. Sex had no effect on outcome, although female patients were significantly older than males. There was a significant effect of age; patients who survived were significantly younger. Fifty-six percent of the patients who died (94 of 168 patients) were older than 60 years of age. There was a significant increase in mortality rates (from $25 \%$ to $63 \%$ ) with increasing age. With regard to trauma mechanism, there were no significant differences, although the rate of low-level falls was higher in non survivors. ${ }^{13}$

\section{Conclusion}

In this study we conclude that male develop larger number of brain injuries than females. Most patients with history of RTA had epidural hematoma. Females most likely develop subdural hematoma. Most patients with brain injury later develop subdural hematoma.

\section{REFERENCES}

1. Gupta PK, Krishna A, Dwivedi AN, Gupta K, Madhu B, Gouri G, Shivani A. CT scan findings and outcomes of head injury patients: A cross sectional study. Journal of Pioneering Medical Sciences. 2011 Oct 1;1(3):78.

2. Jaffee MS, Stokes JW, Leal FO. Posttraumatic stress disorder and posttraumatic stress disorder-like symptoms and mild traumatic brain injury. Journal of rehabilitation research and development. 2007 Oct 1;44(7):895.

3. Langlois JA, Rutland-Brown W, Wald MM. The epidemiology and impact of traumatic brain injury: a brief overview. The Journal of head trauma rehabilitation. 2006 Sep 1;21(5):375-8.

4. Zhang L, Yang KH, King AI. A proposed injury threshold for mild traumatic brain injury. J. Biomech. Eng.. 2004 Apr 1;126(2):226-36.

5. Dowlatshahi D, Demchuk AM, Flaherty ML, Ali M, Lyden PL, Smith EE. Defining hematoma expansion in intracerebral hemorrhage: relationship with patient outcomes. Neurology. 2011 Apr 5;76(14):1238-44.

6. Sharma BR, Harish D. Head injury: The principal killer in road traffic accidents. JIAFM. 2006;28(4):0971-3.

7. Patel N, Kirmi O. Anatomy and imaging of the normal meninges. InSeminars in Ultrasound, CT and MRI 2009 Dec 1 (Vol. 30, No. 6, pp. 559-564). WB Saunders.

8. Kim JJ, Gean AD. Imaging for the diagnosis and management of traumatic brain injury. Neurotherapeutics. 
2011 Jan 1;8(1):39-53.

9. Toyama Y, Kobayashi T, Nishiyama Y, Satoh K, Ohkawa M, Seki K. CT for acute stage of closed head injury. Radiation medicine. 2005 Aug;23(5):309-16.

10. Kleiven S. Why most traumatic brain injuries are not caused by linear acceleration but skull fractures are. Frontiers in bioengineering and biotechnology. 2013 Nov 7;1:15.

11. Bullock MR, Chesnut R, Ghajar J, Gordon D, Hartl R, Newell DW, Servadei F, Walters BC, Wilberger JE. Surgical management of acute subdural hematomas. Neurosurgery. 2006 Mar 1;58(suppl_3):S2-16.

12. Brown CV, Zada G, Salim A, Inaba K, Kasotakis G, Hadjizacharia P, Demetriades D, Rhee P. Indications for routine repeat head computed tomography (CT) stratified by severity of traumatic brain injury. Journal of Trauma and Acute Care Surgery. 2007 Jun 1;62(6):1339-45.

13. Leitgeb J, Mauritz W, Brazinova A, Janciak I, Majdan M, Wilbacher I, Rusnak M. Outcome after severe brain trauma due to acute subdural hematoma. Journal of neurosurgery. 2012 Aug 1;117(2):324-33. 